\title{
Discussions on Changes in Gastric Lymph Drainage in Malignant Gastric Pathology in Terms of Intraoperative Lymphography
}

\author{
Kiss Lorant*, Kiss Roland and Castilia Dobra \\ University Lucian Blaga of Sibiu, Academic Emergency Hospital, Ist Surgical Clinic, Romania
}

Submission: April 12, 2019; Published: May 15, 2019

*Correspondence Author: Kiss Lorant, University Lucian Blaga of Sibiu, Academic Emergency Hospital, Ist Surgical Clinic, Romania

\begin{abstract}
Introduction: The system of drainage proposed by Rouviere was on the whole confirmed; however, one should emphasize the doubling of the hepatic chain, the existence of long collectors which bypass a relay in the left gastric artery, the importance of the posterior gastric artery which transmits the lymphatic of the splenic chain. Finally, the authors emphasize the existence of 3 longitudinal areas on the stomach where the presence or absence of valvules in the subserous collectors orients the lymph towards the lesser or greater curvature of the stomach, which easily explains the onset of isolated carcinomatous adenopathy, situated on the curvature opposite the neoplasm.

Background: In cancer gastric there are several staging systems for lymph node metastasis. The pN classification of gastric cancer is currently based on the distance of metastasis nodes from the primary tumor, and the UICC( Union International Centre le Cancer) has proposed a new classification system based on the number of the involved nodes. The aim of the present study: the author became interested in the lymphatic drainage of the stomach involved by the cancer, in order to attempt to determine for each region the type of drainage and the risk of the cancer spread.

Methods: The author studied 150 dissection including the resected stomach, 230 cases records of gastric carcinoma, 24 lymphographies by ultrafluid Lipiodol, and 100 preoperative in Vivo injections of vital (dye in stomac carcinoma).

Results: The system of drainage proposed however, one should emphasise the doubling of the hepatic chain, the existence of long coleectors which bypass a relay in the left gastric artery, the importance of the posterior gastric artery which transmits the lymphatic of the splenic chain.

Conclusion: Finally, the author emphasyze the existence of 3 longitudinal areas on the stomach where the presence or absence of valvules in the subserous coleectors orients the lymph towards the lesser or greater curvature of the stomach, which easily explains the onset of isolated carcinomatous adenopathy situated on the curvature, opposite the neoplasm. The results from the present study suggest a more extensive operation with gastric resection always combined with systematic lymphadenectomy if no distant metastasis are found. The unpredictability of metastases, the importance of the retrograde lymphatic flow in the etiology of lymphatic metastases regardless of the location of the gastric tumor, suggest the real value of the enlarged lymphadenectomy cases when curative surgery is achievable.
\end{abstract}

\section{Introduction}

The assessment of the extrusive gastric resection and lymphadenectomy during surgery performed in gastric cancer pathology is controversive. It is well known that in the early stages of gastric cancer when the malignant process does not exceed the mucosa, the patient being in an ideal therapeutic stage the cancerous proliferation is already accompanied by neoplazic lymphatic embolie. This early lymphatic invasion brings forward the role of the morphology of the lymphatic system in the neoplazic dissemination and in the genesis of metastasis [16]. Surgeons believe that in the median, only one fifth of the patients with and without systematic lymphadenectomy had positive nodes whereas pathologists found almost three fourths of positive lymph nodes $(72,7 \%)$ in patients with proximal carcinoma of the stomach as compared to those without systematic lymphadenectomy $(30,8 \%)$. The figures for middle and lower third carcinomas were even higher $(63,5$ vs $13,9 \%$ and 75,9 vs $27,1 \%$ ) [7-10].

Gastric cancer is common throughout Europa. In 2000 there were 192.000 diagnoses with 158.000 deaths.

Despite advances in surgical therapy, and in neo or adjuvant chemo-radiotherapy the overall 5-year surgical rate remains poor about 20 per-cent compares with that of 70 per-cent achieved in Japan. Duch an UK $[1,2]$ trials have examined whether extended lymphadenectomy might prove as affective in westem patients. The Dutch trial suggests a survival advantage in the D2 group, 


\section{Cancer Therapy \& Oncology International Journal}

particularly in splenectomy and pancreatectomy are avoided in the patients with prolonged follow-up, but in overall evolution in both trials there was little difference in the early postoperative evolution between western D1 and D2 lymphadenectomy. In an Italian randomized trial (3) the results were similar to those of the Japanese similar advantages for more radical D2 dissection when observed from Germany (4) and the UK (5) [11-16]. Improving the outcome for patients with gastric cancer must also concentrate on better understanding of tumor biology [1723]. The histologic studies shown that the infiltration of the deepest layer of the mucosa were associated with lymph nodes metastasis from $0 \%$ to $12,8 \%$ [24-29]. In the presence of the submucosa invasion, the rate of lymph node metastasis is double compared with mucosal cancer infiltration.

In the early gastric carcinoma, only a diameter of the tumor more than $2 \mathrm{~cm}$ was an independent predictor of lymph metastasis in some publications [30-38]. The assessment on the extensive gastric resection and lymphadenectomy during surgery performed in gastric cancer pathology is not currently remains one of the specialist's concerns [39]. It is well known that in the early stage of gastric cancer, when the malignant process does not exceed the mucosa, the patient being in an ideal therapeutic stage the cancerous proliferation is already accompanied by neoplazic lymphatic embolie. This early lymphatic invasion brings, forward the role of the morphology of the lymphatic system in the neoplazic dissemination and in the genesis of metastasis [40-48].

Surgeons believe that in the median only one fifth patients with and without systematic lymphadenectomy has positive nodes, whereas pathologists found almost three-fourth less of positive lymph nodes $(72,7 \%)$ in patients with proximal carcinoma of the stomach as compared those without systematic lymphadenectomy $(30,8 \%)$. The figures for middle and lower third carcinomas were even higher $(63,5$ vs $13,9 \%$ and 75,9 vs $27,1 \%$ ) [7,8,49-52]. Positive lymph nodes in gastric carcinoma are most common in the peri gastric area and their distribution is clearly related to the site of tumor. In some studies, in patients with carcinoma of the proximal stomach the involved lymph nodes along with the hepatoduodenal ligament were in 9 to $9 \%$ and in 7 to $16 \%$ of patients with carcinoma of the distal part of the stomach $[8,16,53-55]$. The prognosis for gastric carcinoma after curative resection is corelated with the presence or absence of lymph node invasion( $\mathrm{N}+$ ) and serosal invasion $[3,56]$.

Shimodo et al. (cit.18) reported that the depth of invasion and lymph node metastasis correlates with early gastric cancer as follows: in gastric cancer within mucosal invasion and without ulcer, the patients have no lymph node metastasis, in presence of ulcer or invasion of submucosa (within 200 depth only in N1 groups are the metastases present and 5\% of all submucosal cancers deeper than SM1 is the N2 metastasis present.

Accurate classification and staging allow the physician to determine a more accurate treatment, to evaluate the results of management more reliably and compare worldwide statistics which are reported from various institutions and a local, regional and national basis more confidently $[12,43]$.

The anatomical distribution of regional lymphnodes is determined by the Japanese Gastric Cancer Association, but the numbering (N1-16) and grouping (group 1-3) depends on the location and extension of tumors and is too complicated to be used routinely at community hospitals worldwide. Adachi et al publish a classification for lymph node metastasis: level I nodes (perigastric No 1-6), level II nodes (intermediate No 7-9), and level III nodes (distant No 10-16) respective of the tumor location. Adachi et al classified that not the anatomical level but the total number of positive nodes (1-6 vs $>7$ ) was an independent prognostic indicator for node positive gastric cancer. In several studies the number-based N(lymph-node) classification was superior to the classification based on the lymph nodes anatomical location [57-62].

\section{Methods}

The aim of the study is to present the results of research conducted by authors on the effects of gastric cancer on the lymphatic circulation of the organ the lather suffering secondary structural changes. Research has focused strictly on changes which occurred in gastric lymphatic system efferent to the topography of gastric tumor. The distribution of lymph node metastasis was histologically confirmed in 115 cases of gastric cancer in 35-year period (1980-2015). Statistical study of the distribution of perigastric adenopathy was completed with the dissection of 50 operative parts and with the performing of gastric lymphography with ultrafluid Lipiodal in 24 cases following SCHACHATS technique $[1,2,63]$. In view of studying the living human gastric lymphatic system, 100 intraoperative gastric lymphography's were performed using vital dye. This last chapter of the current study refers to the work of gastric lymphatics conducted by the authors; others segments of the study representing the theme of a different publication. Method: after performing the laparotomy blue dye dissolved in water (1\%methlene blue) was injected in different points of the gastric wall, the dye injection being practiced in gastric segments which were to be resected. Before the operation we have an accept for the patients to perform lymphography and we have accepted from the ethics community of the Hospital.

In 30 cases the dye was patent blue dye $1 \%$ concentration. The dye was injected into the subserous layer of the gastric wall, 1,0-1,5 ml was injected in every place with a very fine needle (insulin needle), as the insertion of needle was conducted grazing the gastric wall. The maximum amount of dye use was 5-6 ml. The staining of the lymphatic network accured during a slow injection of dye on 1-10 minutes after injection or following the injection. The efferent lymphatic ways were injected with a rapid spread of the dye toward the lymphatic stations N1, N2 sometimes to stations N3. In most cases one could clearly see the lymphatic network design, indicating the directions of lymphatic 


\section{Cancer Therapy \& Oncology International Journal}

movement. In few cases however we have not achieved any results, as the ways had not been dyed, a situation in which we found no convinging exploration (technical error). With this method we performed intraoperative lymphography in 48 cases. One may mention that the injection of dye be used to perform a more precis intervention as it usually rendems a better images of lymph nodes by their colocation (Figure 1).

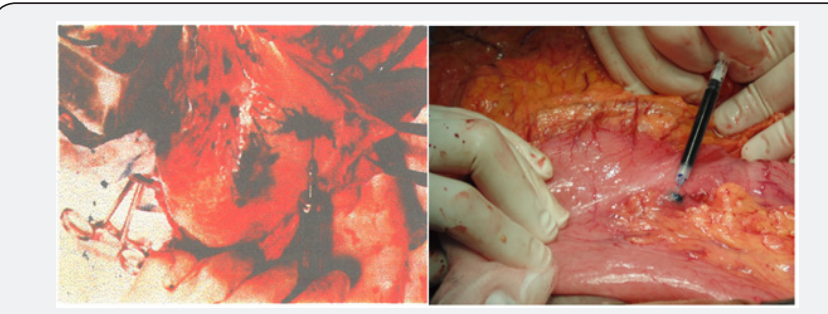

Figure 1: The intraoperative lymphatic staining in gastric cancer.

The injection of dye in the posterior wall was made after the Colo epiploic removal or after sectioning the duodenum which greatly allowed the visualization of the posterior gastric wall. The injection of the bottom region of the stomach was performed only in cases requiring total gastrectomy and in a case of superior polar esogastrectomy through thoracoabdominal way. The spreading of the dye was followed intraoperatively in areas of the stomach where gastric lymphatic ways were not interrupted. After a while the dye would soak into the nearby tissues and on the removed operative part typically were observed only blue spots. As a result, the intraoperative images are not suited for storage.

Results

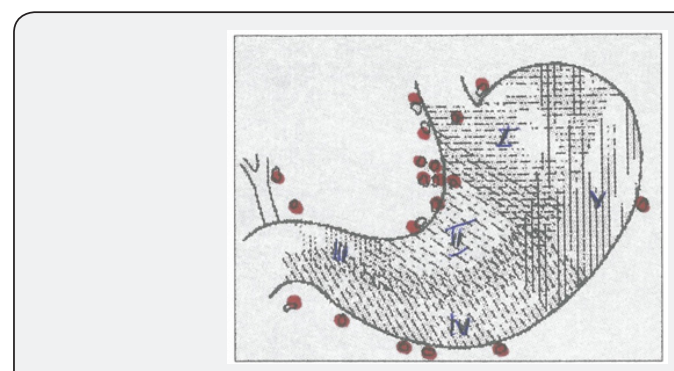

Figure 2: The 5 areas of the lymphatic channel in gastric wahl.

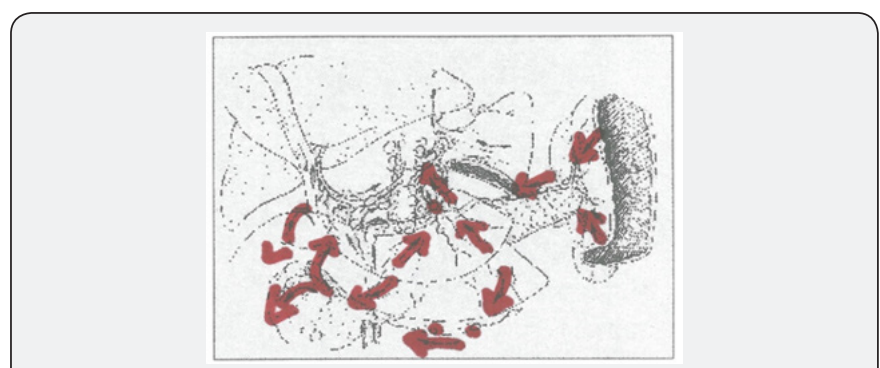

Figure 3: Efferent Channel of the lymph in gastric tumor.

On basis of 100 studied lymphographies the results allowed the following findings. The lymphatic of the vertical segment of the small gastric curvature form two systems (Figures $2 \& 3$ ).
The five lymphatic ways of the stomach: areas I cardial; areas II coronary of the smaller curvature; areas III pylori's; areas IV right gastroepiploic; areas V left gastroepiploic. The first lymphatic stations of the cardial zone (area I) are formed by paracardial nodes which efference can be bidirectional namely: on lymphatic path situated along the coronary to the celiac system and through Para esophagus nodes, to the mediastinum. The first lymphatic stations of the central segment of the smaller curvature (area II) are the parietal nodes of the gastric walls. The efferent branches flow into the nodes of the coronary and celiac artery. These findings show that in the areas I, II the lymphatic through anastomoses in two or three lymph node stations is without a strict delimitation.

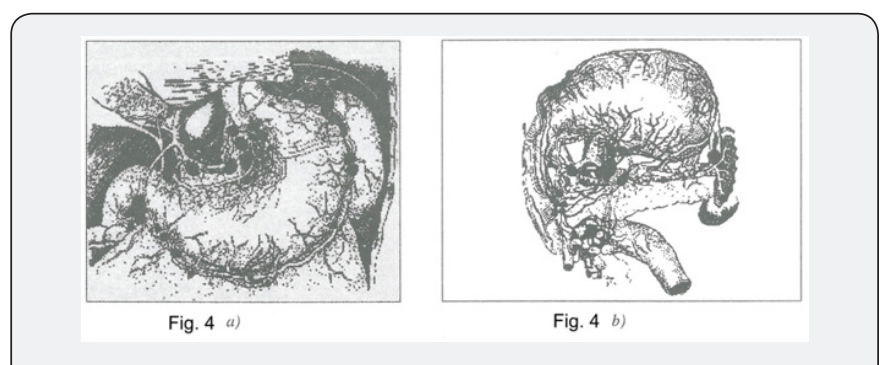

Figure 4: lymphatic system of the stomach after Polya-Navraty.

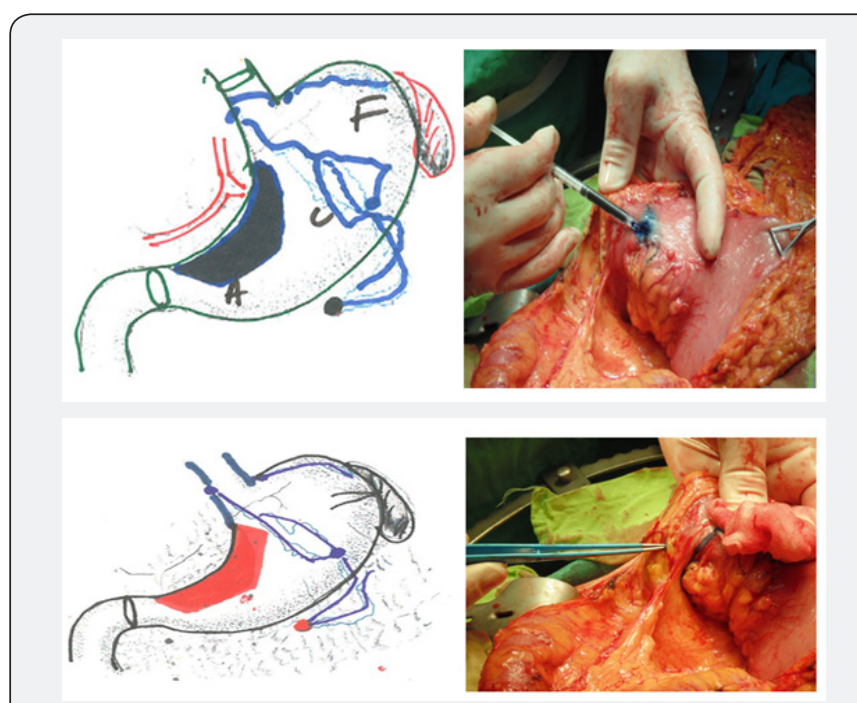

Figure 5:

A. Bi-directional diffusion of the great injected dye in the gastric wall in the vecinity of the grater gastric curvature.

B. The dye injected in vivo, shown the bidirectional diffuse of the dye in the neighbourhood of the greater curvature.

C. Bi-directional diffusion of the great injected dye in the gastric wall in the vecinity of the grater gastric curvater.

D. The dye injected into the fundic region near the greater gastric curvature often fills the lymphatic paths associated with paracordial nodes.

In the cardia and pylorus, the efferent lymphatic anastomoses are already in lymph node stations one. These findings confirm the practical validity of the classical descriptions of Rouviere and Caller (Figures $4 \mathrm{a} \& 4 \mathrm{~b}$ ). The lymphatic network of the 


\section{Cancer Therapy \& Oncology International Journal}

gastric wall is characterized by multiple communications between different gastric territories, with bidirectional diffuse. The matier is emphasized in the image marked (1). The changes in the limited areas which may occur in some cases are shown in image $\operatorname{nr}(5 \mathrm{a})$ shown the localization of the tumor (the real area of the tumor) (Figures 5a-5d). The dye injected into the fundic region near the greater gastric curvature often fills the lymphatic paths associated with paracordial nodes (Figures 6a6c). Lymphatic network colored after the dye injected in different areas of the stomach. The dye injected in the prepyloric area fills a multidirectional lymphatic network. Figure 7 If injected in the presence of a tumor compressing the great curvature (red area) it distributes multidirectional in the efferent lymphatic paths.
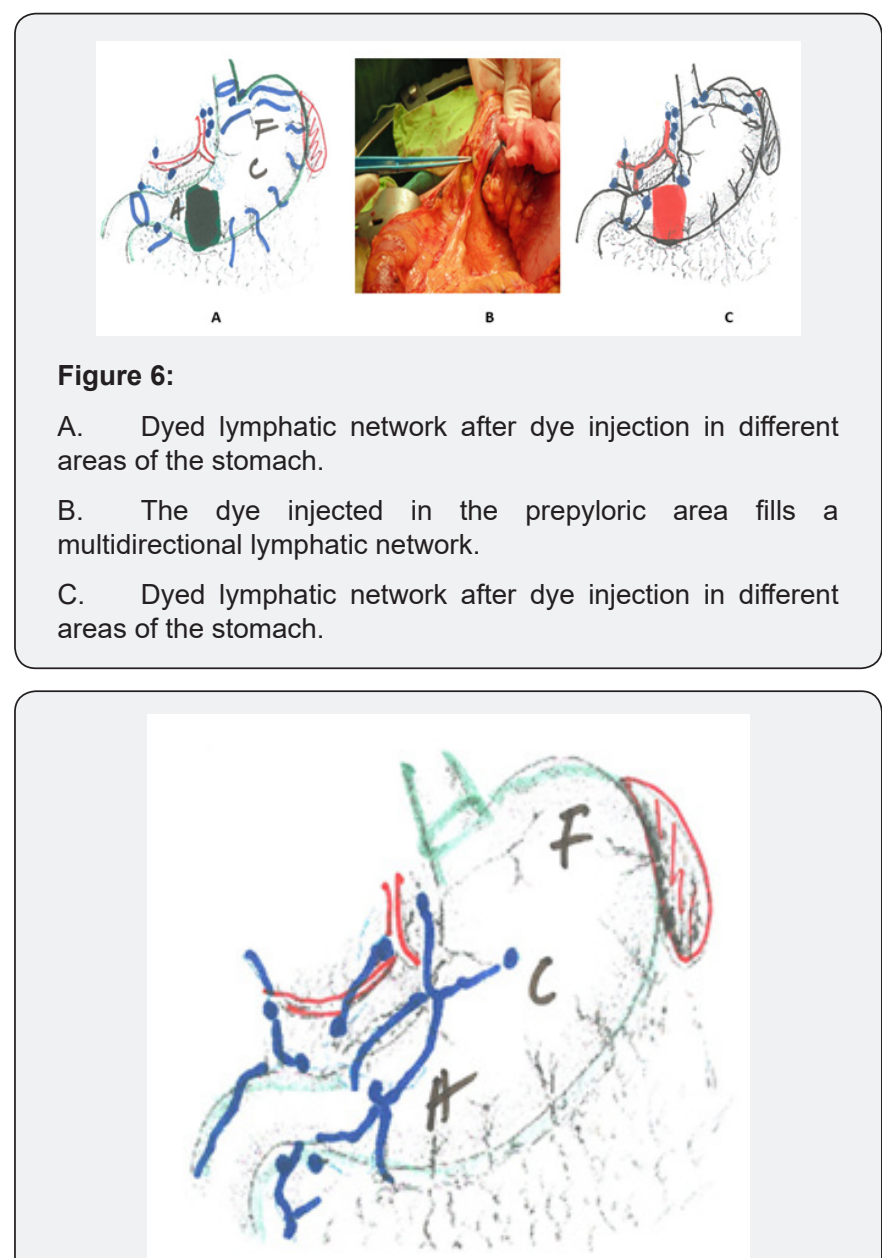

Figure 7: Image reproduction of the multi-directional prepyloric lymphatic network.

Regarding the efferent lymphatic ways of some gastric areas, our observations show that the prepyloric segment of the lesser gastric curvature has the most lymphatic ways, one of these were on short way directly to the lymph node station of the liver helium (Figures 7a \& 7b). In this case we notice a lymphatic way that after reaching (page 8) the lesser curvature will lead retro duodenal. Other vessels are leading to the hepatoduodenal ligament all the way to the hepatic hilum. The majority of lymphatic vessels lead toward upper pyloric vessels and celiac tru only in two cases have the lymphatic paths been fill which lead from the lesser curvature toward suprapancreatic nodes, following the retro pancreatic way by splenic hilum. Such lymphatic vessels have been described by JAMIESON-DOBSON. In one case of tumor of the lesser gastric curvature, such a lymphatic branch is divided at the greater gastroduodenal curvature, one of their crossing the anterior part of the duodenum which then flows within the retro duodenal nodes Figure 8. The dye which was injected near the tumor emphasizes the lymphatic network developed around the tumor. The arrows indicate the presence of a lymphatic with a known path. These lymphographic findings reinforce the clinical observations according to which in the presence of prepyloric tumor, the lymphatic dissemination is multidirectional. The poorest area of lymphatics the gastric "V" area, located in the medium and superior $1 / 3$ of the greater curvature named "mute area" as in this particular area the incidence of malignant tumors is reduced the efferent lymphatic vessels of this area lead toward the splenic hilum which was demonstrated by RIO BRANCO.

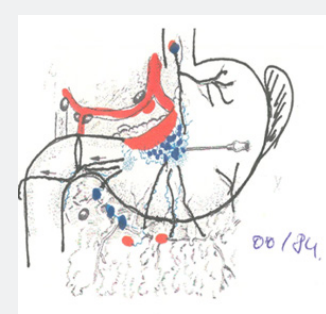

A

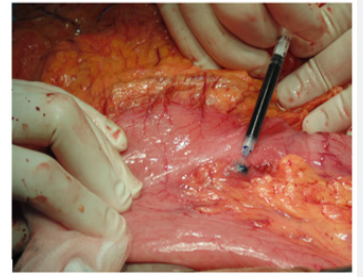

B
Figure 8:

A. Tumor of the lesser gastric curvature, such a lymphatic branch is divided at the greater gastroduodenal curvature, one of their crossing the anterior part of the duodenum which then flows within the retroduodenal nodes.

B. Intraoperative image of lymphatic diffusion from the lesser gastric curvature to the duodenum.
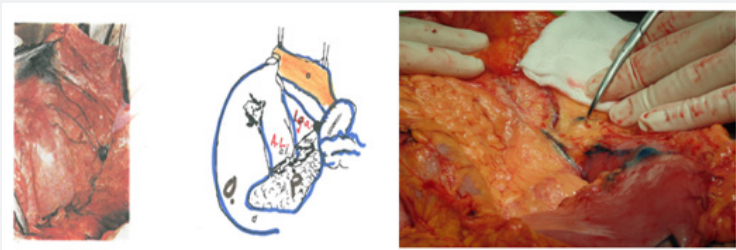

Figure 9:

A. Lymphatic Tract; O: anertum; I.g: Ligamentum gastrocolicum; m.c: mesocolon; P: pancreas; a.I: arteria liazalis; t: tumora; d: duodenum.

B. Intraoperative with special lymphatic flow.

In a case of our own, we notice the presence of an efference which was new to this territory. After administering the dy within the distal part of the gastric field $V$, a lymphatic network has been drawn in the dorsal part of the gastrocolic ligament to the colon, flowing in a paracolic node. After a peripancreatic 


\section{Cancer Therapy \& Oncology International Journal}

path its efferent branch has flow to the origin of the splenic artery. This observation demonstrates the existence of multiple variants in gastric lymphatic path (Figure 9). We have obtained beautiful images in limites plastica while injecting the dye in those areas where the tumor has not infiltrated the sub serosal area. In Figure 10, on can see the sub serosal network being filled with dye thus forming large vessels, only near the gastric curvatures.

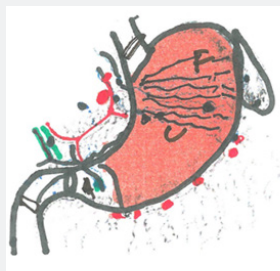

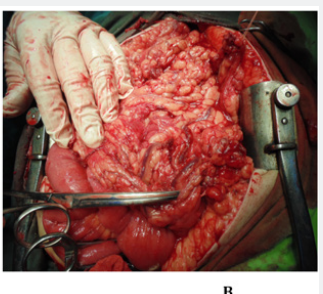

Figure 10:

A. Lymphatic filling in the plastic linit.

B. IOP the lymphatic diffusion only near the gastric curvatures.

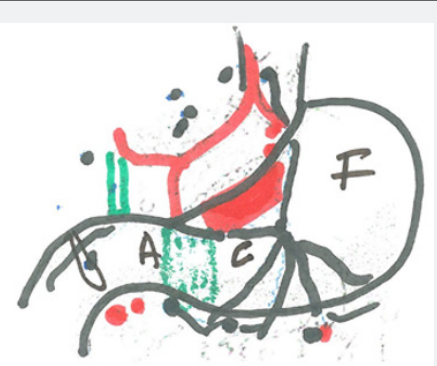

Figure 11: Lymphatic filling during the intervention for gastric ulcer.

In the tumor involves the serosa, the lymphatics became thrombosed and will develop new paths the latter bypassing the tumor, which will then pour in the neighboring nodes on the same curvature (Figure 11). The lymphatic pathways which go to the small curvature elide the tumor. We have often observed that in tumors the lymphatic circulation is reversed with the lymphatic spread to the across curvature, retrograde lymphatic flow, something we have not seen in a normal stomach. Moreover, any attempt of manual compression, of the region has caused the breakage of lymphatics without the removal of the dye itself. In many of the studied groups, we have noticed on which was caused the diversion of circulation metastases located in lymph nodes are along the lymphatics. The tumoral tissue destroys intraglandular capillary network. While there is lymphatic tissue along the tissue, the lymphatic circulation is not stopped in the node however, the dye only marks the healthy area. This shows a completely invaded lymph node will change the direction of the lymphatic flow. This formulation is an agreement with a finding in our case with central tumor after which injecting the dye in the peritumoral area, the lymphatic filling was noticed in a lymphatic vessel along the great gastric curvature which was interrupted in the vicinity of a metastatic node, deviating toward the small curvature of the duodenum (Figure 12).

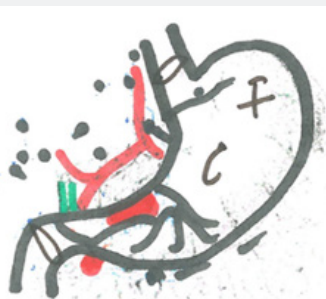

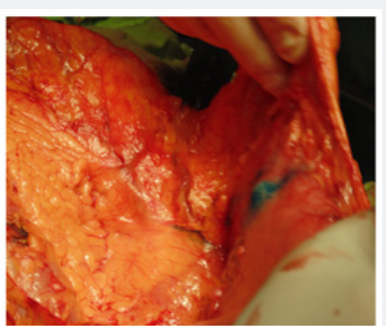

B
Figure 12:

A. Lymphatic filling. Tumoral metastasis deviates lymphatic circulation.

B. The tumoral metastasis deviating the duodenum.

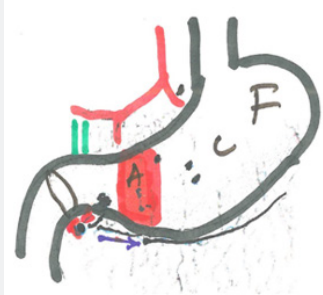

A

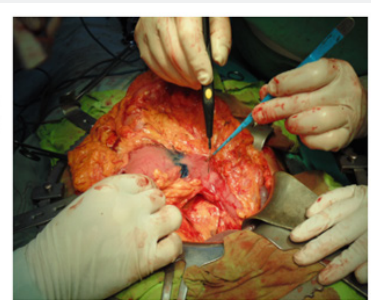

B
Figure 13:

A. Lymphatic filling in case of prepyloric tumor. Tumor metastasis determines the appearance of retrograde lymphatic flow.

B. The retrograde lymphatic diffusion in prepiloric tumor.

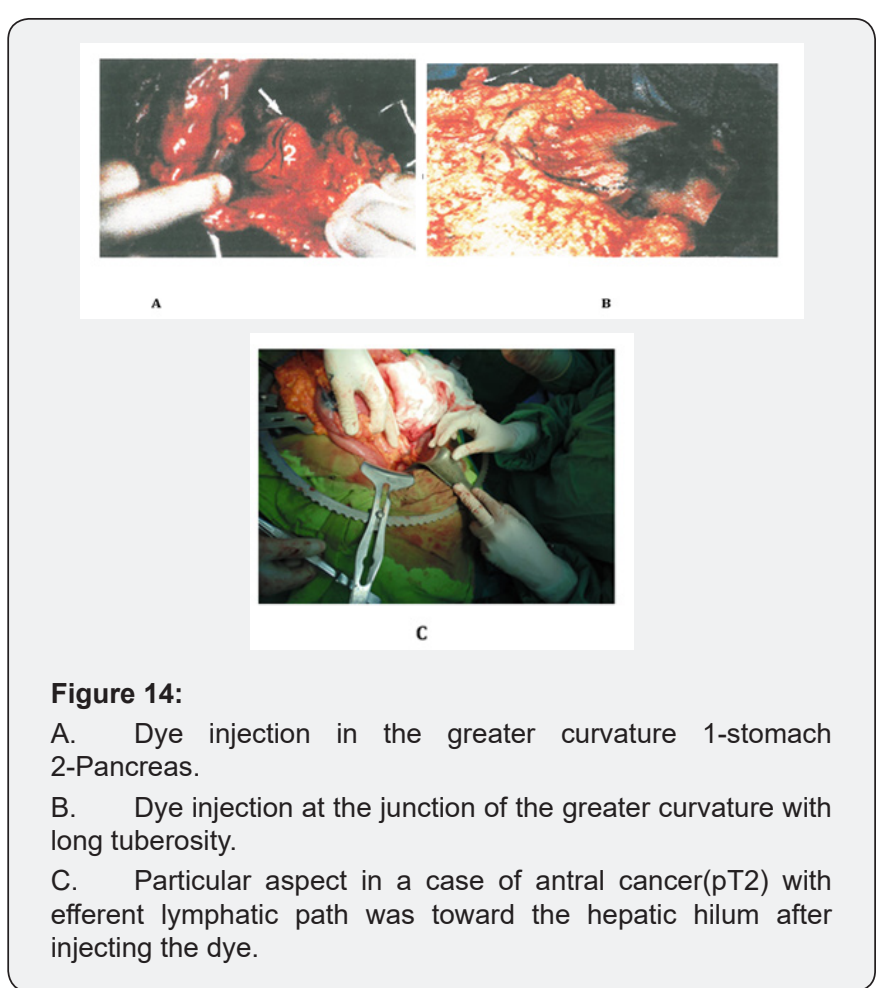




\section{Cancer Therapy \& Oncology International Journal}

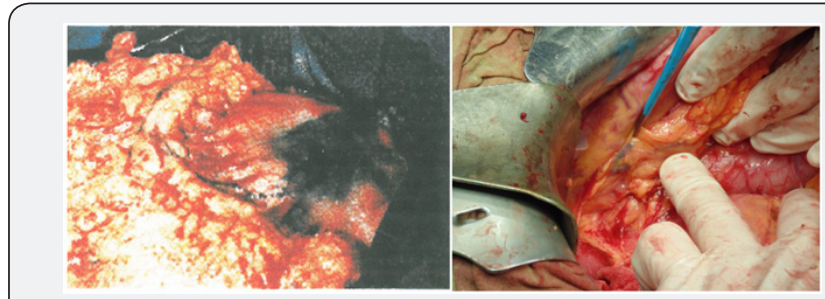

Figure 15: Dye injection at the junction of the greater curvature with long tuberosity.

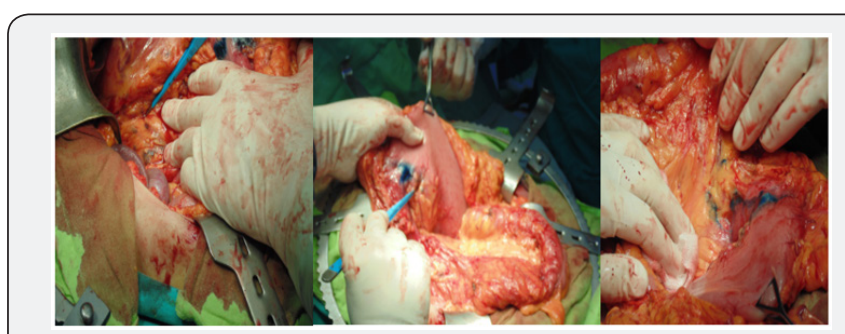

Figure 16: Lymphatic channel and gastrocolic ligament.

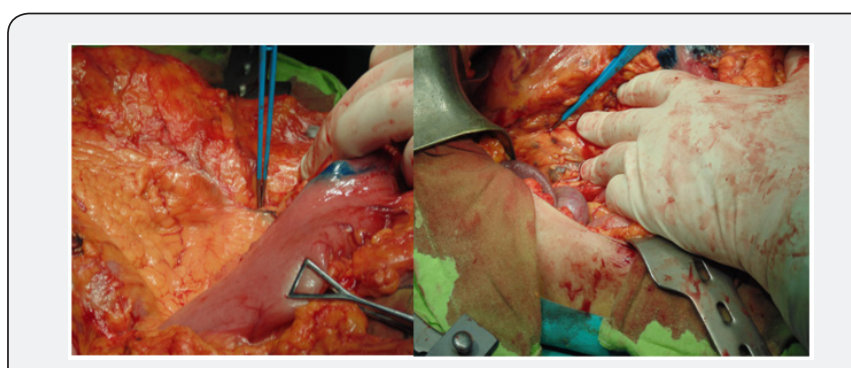

Figure 17: The dye diffusion on the small and great gastric curvature.

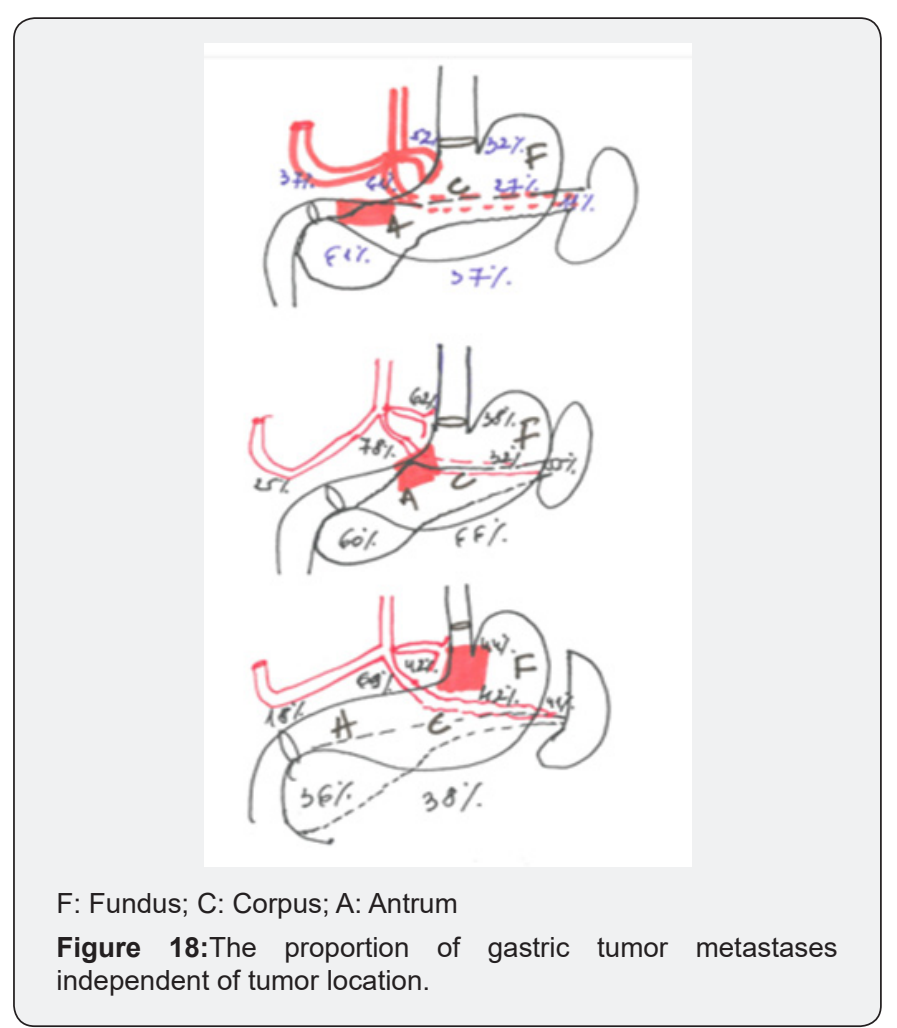

The different case (Figure 13) showing a circular prepyloric tumor the injection of dye near the duodenal edge was followed by the staining of lymphatics, which shead within the sub pyloric nodes as the lymphatic flow was followed by retrograde direction the great gastric curvature. The last two observations mentioned above reinforces Nishimura's observation creating a prerequisite for metastatic invasion. The gastric lymphatic system as well as the possibility of the retrograde lymphatic circulation in the tumoral pathology allows the evolution lymphatic metastasis in any tumor territory. In some cases, we have noted the presence of distant metastasis, given that the peritumoral nodes were (N-) histological. These metastases we have considered as "skip metastases" (Figure 14). We have noticed a particular aspect in a case of antral cancer(pT2) with efferent lymphatic path was toward the hepatic hilum after injecting the dye. Is it a short way to the direct dissemination in 9th station? (Figures 15-18).

\section{Discussion}

The results obtained through applied in the study of tumoral gastric lymphatic circulation allow few comments (Figure 18). In papillary tumors, the lymphatic metastasis was predominant in the celiac and subpiloric group, as well as in the splenic hilum in $11 \%$ of cases. These findings reinforce the importance of retrograde circulation in tumoral gastric surgery [3-5,37,64-70]. We have found $36 \%$ of cases with tumor of the cardia, the presence of subpiloric lymph node metastasis and in $45 \%$ lymphatic metastasis in the splenic hilum which highlight the importance of retrograde lymphatic flow in loco regional metastasis $[29,71]$. In the presence of medio gastric tumors, the metastasis was multidirectional including all curvatures, splenic hilum and retro pancreatic current which shows the existence of a multidimensional continuation in malignant lymphatic dissemination through lymphatic ways which are efferent to the tumor.

Despite the undeniable [31] existence of lymphatic anastomosis histopathological distinguished, the pylorus is a serious barrier against lymph progression. In over $85 \%$ of our cases, the prepyloric injection of dye in the direction of the duodenum has revealed the formation of a ring that stretches over marginal supra and subpiloric area, representing a true barrier. Considering the results, we have obtained Figures 2 $\& 3$ as well as the classic anatomic data Figures $4 \mathrm{a} \& 4 \mathrm{~b}$ three territories with gastric lymphatic drainage have been confirmed, with clinical significance in tumoral pathology.

a. The coronary territory, described by Rouvier which covers the entire surface of the lesser curvature, comprising the upper two thirds of the horizontal portion of the stomach.

b. Rouviers hepatic territory stretched throughout the great curvature and the horizontal part of the lesser curvature, the angle and lower vertical portion of the lesser curvature. 


\section{Cancer Therapy \& Oncology International Journal}

c. The splenic territory which comprises two left thirds of the great tuberosity and the first two inches of the middle portion of the greater gastric curvature.

This scheme regarding drainage is valid for the study resection pieces as in the living man, is suffers numerous readjustments, primarily due the dynamics of lymphatics digestive viscera which is linked to peristaltis and the presence of lymphatic valves which direct the lymphatic flow in different areas. This explains the situation which we observed on presence of "paradox" metastases a synchronous multicentric lymphatic dissemination.

In the light of the above observation one can divide each gastric face in the proximity of the lesser curvature and a median strip. The lymphatic located in one of the expense areas, are conducted corresponding curvature through the movement of the valves as subserous collaterals are in continuity from one stomach curvature to another only the lymphatic vessels before the curvature have valves. The above analysis has been deduced from in vivo aspects of intraoperative lymphography. The lymphography's which were performed on resection parts with lipoidal dye to the lock of peristaltic, the lymphatic valves were in a few cases forced [63] by injection counter. The aspect detected during the lymphography performed intraoperatively, may explain the presence of lymph node metastasis located on the curvature opposite to the neoplasm. This is explained by the fact that the hyper pressure down streaming causes the cancerous cells to be showed and blocked from streaming to the intermediate evaluated area. These areas are caught in the lymphatic station through valuate collectors which will head the lymph in different directions where the lymphatic paths are not blocked by malignant cells and still function physiologically.

As opposed to the schema of classic lymph drainage of the stomach, which were established through the studies of corpses the in vivo gastric lymphatic drainage is partially changed by the mandatary presence of intermediate areas, which are interposed between the three known classical areas so that the coronary and splenic territory may include the intermediate areas $[6-8,11$ 13]. Of course, the drainage of tumoral cells may spread in every direction as shown in the results of the in vivo lymphography [64-66,71,72]. There is however a preferential drainage heading to the classic node group. Znniser et al. $[73,66,74,54]$ in a study regarding the evaluation of the spread in the gastric wall has found a wide variation in it extend. The tumor spread can be observed through the intramural lymphatic sor in the sub serosal layers, with local extension intra the esophagus or the duodenum $[3,7,25,30,31,73,75,76]$.

In the present study, we have observed that the extension into the duodenum was in the majority of cases through the muscular layer with direct infiltration of the lymphatics channel, and through the lymphatics from the serosa. In all observed cases the extension into the duodenum was generally with a limited extent.
In the proximal gastric tumors, the in vivo blue dye showed the diffusion of the dye into the esophagus wall, were in the majority of cases through the submucous lymphatic channels. In the present study, the stained nodes were most common in the perigastric area and their distribution was clearly related to the site of the tumor. This observation is similar with other studies $[3,25,26,30,31,61,74,77-80]$.

Frequently however the lymph node stations were involved for from the primary, that is along the hepatoduodenal ligament, in $5-19 \%$ of patients with proximal carcinoma, and in $6-16 \%$ of patients with carcinoma, and $6-16 \%$ of patients with carcinoma of the distal part of the stomach $[2,5,17,18,30,31,73]$. The present study confirms the results as published by Keller et al. However insufficient clearance of micro metastasis deposits within regional lymphatic vessels and surrounding tissue seems to be the main cause of the stomach $[18,19,67,80-85]$. We found it interesting to follow the distribution of lymphatics from the juxta parietal nodes and establish appreciate regrouping its collectors. One could notice a halving of the hepatic lymphatic chain and drainage to be collectors from a relay in gastric coronary nodes and the importance of the posterior gastric artery which sustains the splenic node chain $[1,4,24,25,31,32,63,86]$.

The prognostic significance of lymph node dissection in the gastric carcinoma remain controversial, but some studies suggested that the extend of lymph node dissection (D1, D2 orD3) is an important factor associated with the early or late recurrence [87-92]. Lymph node metastasis decisively affects prognosis in gastric carcinoma, and the operative clearance of the lymphatics is importance and requires a thorough surgical training if it is to be done effectively and safely [93-97].

\section{References}

1. T Sano (2007) Treatments for curable gastric cancer. Br J Surg 94(3): 263-264.

2. Kim JH, Park SS, Kim J, Boo YJ, Kim SJ, et al. (2005) Surgical outcomes for early gastric cancer in the upper third of the stomcah. Am Surg 30(10): 1870-1876; discussion 1877-1878.

3. Higashi $\mathrm{H}$, Natsugoe $\mathrm{S}$, Ishigami $\mathrm{S}$, Uenosono $\mathrm{Y}$, Matsumoto $\mathrm{M}$, et al. (2003) Distribution of lymph node metastasis including micrometastasis in gastric cancer with submucosal invasion. World Surg 27(4): 455-459.

4. Suphan Erturk, Yilmaz Ersan, Yusuf Cicek, Gulen Dogusoy, Mustafa Senocak, et al. Effect of simultaneous splenectomy on the survival of patients undergoing curative gastrectomy of proximal gastric carcinoma. Surg today 33(4): 254-258.

5. Shinz I, Hynya S, Nobutomo M (2011) Lymph node involvement in Proximal gastric carcinoma. World Surg 33: 1687-1692.

6. Sanpathi, SO JB, Ho ky (2006) Endoscopic ultrasonography for gastric cancer: does it influence treatment? Surg 20: 559-562.

7. CN Shieri A, Weeden S, Fielding, Bancewic, Craven J, et al. (1991) Patient survival after D1 and D2 resections for gastric cancer: long term results of the MRC randomized surgical trial. Surgical co-operative Group. Br.7 Cancer 79(9-10): 1522-1530.

8. Parkss, Park M, Kim H, Kim WB, Lee J, et al. (2006) Prognostic factors for patients with node-negative gastric cancer: Can extended lymph node dissection have a survival benefit? Surg Oncol 94(1): 16-20. 


\section{Cancer Therapy \& Oncology International Journal}

9. Schacht U, Junemann A, Becker HJ, Huth F, Palomba PP, et al. (1976) Ergebnisse der Magenlumphographie unter besonderer Berbucksichtigung des Magenkorzinoms. Dtsch Med Wschr 101: 725750.

10. R Sarrazin, A Pissas, JF Dyon, Y Bouchet (1979) Le drainage lymphatique de l'estomac. J Surg 116: 583-590.

11. Beahrs (1992) American Commithe on cancer, American Society Manual for staging of cancer, $\left(4^{\text {th }}\right.$ edn $)$, Lippincot, Philadeplhia, USA.

12. Sobin LH, Wittekimd C (1997) International Union against Cancer (1997) TNM classification of malignant tumours, $5^{\text {th }}$ Wiley-Liss, New York, USA.

13. Park JM, Kim JH, Park SS, Kim SJ, Mok YJ, et al. (2008) Prognostic factors and Avaibility of D2 lymph node dissection for the patients with stage II Gastric cancer: Comparative analysis of subgroups in stage II. World Surg 32(6): 1037-1044.

14. Siewert JR, Kestlmeier R, Busch R, Böttcher K, Roder JD, et al. (1996) Benefits of D2 lymph node dissection for patients with gastric cancer and PN0 and pN1 lymph node metastasis. Surg 83(8): 1144-1147.

15. Wanebo HJ, Kennedy BJ, Chmiel J, Steele G Jr, Winchester D, et al. (1993) Cancer of the stomach.A patient care study by the A American College of Surgeons. Ann Surg 218(5): 583-592.

16. Yang SH, Zhang YC, Yang KH, Li YP, He XD, et al. An evidence-based medicine review of lymphadenectomy extent for gastric cancer. (2009) Ann Surg 197(2): 246-251.

17. Boise V, Pigmon J, Saint Aubert B, Basser P, et al. (2007) J Clin Oncol 25: 4510 .

18. John S Macdonald, Stephen R Smalley, Jacqueline Benedetti, Scott A Hundahl, Norman C Estes, et al. (2001) Chemotherapy after surgery compared with surgery for adenocarcinoma of the stomach or gastroesophagial junction. N Engl Med 345: 725-730.

19. Sakuramoto S, Sasako M, Yamasuchit, Kinoshitat, Masashi Fujii, et al. (2007) Adjuvant chemotherapy for gastric cancer with S 1. N.Engl 7 Med 357: 1810-1820.

20. Lee SY, Hwang I, Park YS, Gardner J, Ro JY (2010) Methastatic lymph node ratio as a prognostic factor in gastric cancer. Eur Surg Oncol 31(1): 59-66.

21. Saito H, Furumoto Y, Osaki T, Yamada Y, Fukuda K, et al. (2008) prognostic significance of the ratio between metastatic and dissected lymph nodes in patients with advanced gastric cancer. Surg Oncol 97(2): 132-135.

22. Xu DZ, Geng QR, Long ZJ, Zhan YQ, Li W, et al. (2009) positive lymph node ration is an independent prognostic factor in gastric cancer after D2 resection regardless of the examined number of lymph nodes. Ann Surg Oncol 16(2): 319-326.

23. Persiani R, Rausei S, Antonacci V, Biondi A, Casella F, et al. (2009) Metastatic lymph node ratio:new staging system for gastric cancer World Surg 33(10): 2106-2111.

24. Gotoda I, Yamamoto H, Soetik R (2006) Endoscopic submucosal dissection of early gastric cancer. Gastroenterol 41(10): 929-942.

25. Scs (2004) guidelines for diagnosis and treatment of carcinoma of the stomach, ( $2^{\text {nd }}$ English Edn), p. 1-12.

26. Smith DD, Schwarz RR, Schwarz RE (2005) Impact of total lymph node count on staging and survival after gastrectomy for gastric cancer:data from a large US population database. Clin Oncol 23: 7114-7124.

27. An JY, Baik YH, Choi MG, Noh JH, Sohn TS, et al. (2007) predictive factors for lymph node metastasis in early gastric cancer with submucosal invasion. Ann Surg 246(5): 749-753.

28. Desiucim, Calvo F (2006) Survival of early gastric cancer in a specialized European center. Which lymphadenectomy is necessary? World Surg 30(12): 2193-2203.
29. Pedrazzani C, Sivins A, Ancans G, Marrelli D, Corso G, et al. (2010) Ratio between metastatic and examined lymph nodes.May have a low clinical utility in gastric cancer patients treated by limited lymphadenectomy:results from a single center experience of 526 patients. World Surg 34(1): 85-91.

30. Wu CW, Hsiung CA, Lo SS, Hsieh MC, Chen JH, et al. (2006) Nodal dissection for patients with gastric cancer: a randomized Controlled trial. Lancet Oncol 7(4): 309-315.

31. Kong SH, Kim JW, Lee HJ, Kim WH, Lee KU, et al. (2009) The safety of the dissection of lymph node stations 5 and 6 in preserving gastrectomy. Surg Oncol 16(12): 3252-3258.

32. Kong SH, Lee HJ, Ahn HS, Kim JW, Kim WH, et al. (2012) Stage migration Effect on Survival in gastric cancer surgery with extended Lymphadenectomy. Surg 255(1): 50-58.

33. Jiping Wang et al. (2012): 578-585.

34. Jemal A, Siegel R, Xu J, Ward E (2010) Cancer statistics 2010. CA cancer Clin 60(5): 277-300.

35. Siewert JR., Harder J, Allogower M (1990) Berlin, Springer, pp. 675748.

36. Diteler HI, Siewert JR (1991) Endoscopie 1: 18-22.

37. Brito MJ, Williams GT, Thompson H, Filipe MI (1994) Thompson H. Expression of PB in early(T1) gastric carcinoma and precancerous adjacent mucosa Gut 35(12): 1697-1700.

38. Bonenkamp JJ, Hermans J, Sasako M, van de Velde CJ, Welvaart K, et al. (1999) Extended lymph-node dissection for gastric cancer. Dutch Gastric Cancer Group. N Engl J Med 340(12): 908-914.

39. Usika S, Chastas Cl, Houry S, Lacaine F, Seuguier M, et al. (1989) L'envahissement lymphatique seulfactor prognostique apres resection avisee de l'estomac. World J Surg 13: 118-123.

40. Maruyama K, Sunvem P, Sasabo K, Kinoshita T (1989) Lymph node metastases of gastric cancer. General patiern in 1931 patients. Am Surg 210(5): 596-602.

41. Houtefeuille P, Piel K (1982) Compared azathioprine efficacy in ulcerative colitis and in Crohn's disease. Gastroenterol Clin Biol G 26(4): 849-856.

42. Kaibara M, Sumi K, Yanekava N (1990) Does extensive dissection of lymphnodes improve the results of surgical treatment of gastric cancer. Am J Surg 159(2): 218-221.

43. Ballschweiller E, Balttcker K, Manyama K, Siewert JR (1992) Preoperative assessment of lymphnodes metastases in patients with gastric cancer evolution of the Maruyama computer program. Br. J Surg 79: 156-160.

44. Maruyama K, Gunvén P, Okabayashi K, Sasako M, Kinoshita T (1989) Lymph node metastases of gastric cancer general patiern in 1931 patients. Am Surg 210(5): 596-602.

45. Parikh D, Johnson M, Chagla L, Lowe D, McCulloch P (1996) D2 gastrectomy lessons from a prospective audit of the learning curve. $\mathrm{Br}$ J Surg 83(11): 1595-1594.

46. Rouviere H (1932) Les lymphatiques de l; homme. Paris.

47. Yao JC, Schnirer II, Chiang SS (2000) Different patterns of gastric cancer localization in men and women. Proc Anno Meet sami Soc Clin Oncol 19: 6529.

48. Wanebo HJ, Kennedy BJ, Chmiel J, Steele G Jr, Winchester D, et al. (1993) Cancer of the stomach. Ann Surg 218(5): 583-592.

49. Yoon SS, Yang HK (2009) Lymphadenectomy for gastric cancer: should West meet East ? Oncologist 14(9): 871-882.

50. Kim JP, Lee JH, Kim SJ, Yu HJ, et al. (1998) Clinicopathologic characteristics and prognostic factors in 10783 patients with gastric cancer. gastric cancer 1(2): 125-133. 


\section{Cancer Therapy \& Oncology International Journal}

51. AZ (2002) cancer staging manual New York, USA.

52. Celem O, Yildirim E, Berbeloglu U (2007) Prognostic impact of positive lymph node in gastric carcinoma. Surg Oncol 96(2): 95-101.

53. Peter H, Stephan S (2003) Seminar: Gastric Cancer. Lancet 362: 305315

54. Barbour AP, Rizk NP, Gonen M, Tang L, Bains MS, et al. (2007) Lymphadenectomy for adenocarcinoma of the gastroesophageal junction (SE): impact of adequate staging on outcome. Ann Surg Oncol $14(2): 306-316$.

55. Grise K, Mcfadden D (1998) Gastric cancer: three decades of surgical management. Am Surg 64(10): 940-943.

56. D’Angelica M, Gonen M, Brennan MF, Turnbull AD, Bains M, et al. (2004) Patterns of initial recurrence in completely resected gastric adenocarcinoma. Ann surg 240(5): 808-816.

57. Sivins A, Pedrazzani C, F Roviello, G Ancans, M Timofejevs et al. (2009) Surgical treatment of gastric cancer in Latvia. Results of centralized experience. Eur Surg Oncol 35(5): 481-485.

58. Lee JH, Ryu KW, Kim CG, Kim SK, Choi IJ, et al. (2005) Comparative study of the subserosal versus submucosal dye injection method for sentinel node biopsy in gastric cancer. 31(9): 965-968.

59. Maruyama K, Sasako M, Kinoshita T, Sano T, Katai H, et al. (1999) Can sentinel node biopsy indicate rational extent of lymphodenectomy in gastric cancer surgery. Fundamental and new information on lymphnode dissection. Surg 384(2): 149-157

60. Miwa K, Kinami S, Taniguchi K, Fushida S, Fujimura T, et al. (2003) Mapping sentinel nodes in patients with early stage gastric carcinoma. Surg 90(2): 178-182.

61. Tóth D, Kincses Z, Plósz J, Török M, Kovács I, et al. (2011) Value of sentinel lymph node using a blue dye-only method in gastric cancer: a single center experience from North -East Hungary. Gastric Cancer 14(4): 360-364.

62. Japanese Gastric cancer Association (2011) Japanese gastric cancer treatment guidelines 2010 (ver. 3). Gastric Cancer 14(2): 113-123.

63. Kodera Y, Sasako M, Yamamoto S, Sano T, Nashimoto A, et al. (2005) Identification of risk factors for the development of complications following extended and super extended lymphadenectomies for gastric cancer. Surg 92(9): 1103-1109.

64. L Kiss, C-nica Chirurgia (2002) 97: 341-349.

65. Brar SS, Mahar AL, Helyer LK, Swallow C, Law C, et al. (2014) Process of Care in the multidisciplinary treatment of gastric cancer. Jama Surg 149(1): 18-25.

66. Martin RC $2^{\text {nd }}$, Jaques DP, Brennan MF, Karpeh M (2002) Achieving Ro resection for locally advanced gastric cancer is it worth risk of multiorgan resection. J Am Coll Surg 194(5): 568-577.

67. Smith BR, Stabile BE (2006) Agressive D2 lymphadenectomy is required for accurate pathologic staging og gastric adenocarcinoma Am Surg 94: 221-227.

68. Siewert JR, Bottcher K, Stein HJ (1998) Relevant prognostic factors in gastric cancer: ten-year results of the German Gastric Cancer Study. Ann Surg 228(4): 449-461.

69. Jlfet Sangun, Cornelis IH, Vancl Weede (1995) Results of completed clinical trials for gastric cancer. Euro J Surg Oncol 21: 588-590.

70. Hölscher AH, Drebber U, Mönig SP, Schulte C, Vallböhmer D, et al. (2009) Early gastric cancer: lymph node metastasis starts with deep mucosal infiltration. Ann Surg 250(5): 791-797.

71. Kiss Roland (2014) Determinarea nodulului limfatic prin metode in vivo, ex-vivo in cancerele digestive. (Edn), Universitas, p. 37-49.

72. Dezso, Miklós Török, Zsolt Kincses, László Damjanovich (2013) Prospective comparative study for the evaluation of lymphnode involvement in gastric cancer. Maruyama P. Computer program versus sentinel lymph node biopsy. Gastric Cancer, pp. 201-207.

73. Siewert R, Bottcher K, Roder D, Busch R, Hermancek P, et al. (1993) German Gastric Carcinoma Study Group. Prognostic relevance of systemic lymph node dissection in gastric carcinoma. Br 7 Surg 80(8): 1015-1018.

74. Charles EW, Charles RS, Kelly M, Robert CS Martin (2008) Adquate lymphadenectomy results in accurate nodal staging without an increase in morbidity in patients with gastric adenocarcinom. Am Surg 196(3): 413-417.

75. Bonenkamp I, Hermans J, sasako M, Van de Veldect, Welvaart K, et al. (1999) Dutch Gastric Cancer Group. Extended lymph-node dissection for gastric cancer. N Engl Med 340(12): 908-914.

76. Deguili M, Sasakom, Ponti A, Calvo F (2004) Survival results of a multicentre phase II study to evaluate D2 gastrectomy for gastric cancer. Br 7 Cancer 90(9): 1727-1732.

77. Karpeh MS, Leon L, Klimstra D, Brennan MF et al. (2000) Lymph node staging in gastric cancer is location more important than Number. An analysis of 1084 patients. Ann Surg 232(3): 362-371.

78. Jamieson K, Dobson F (1907) The lymphatic system of the stomach. Lancet 169: 1061-6(cit.74).

79. Hohembeeser P, Sretschel S (2003) Gastric cancer. Lancet 362: 305315.

80. Schlas MC, Bembenek A., Schulze T (2004) Sentinel node biopsy in gastro intestinal tract cancer. Eur Cancer 40: 2022-2132.

81. Siewert R, Sendler A (2000) Potential and facility of sentinel node detection for gastric cancer. Recent Results Cancer Res 15: 259-269.

82. Hiratsuka M, Miyashiro I, Ishikawa O, Furukawa H, Motomura K, et al. (2001) Application of sentinel node biopsy to gastric cancer surgery. Surgery 129(3): 335-340.

83. Ryu KW, Lee JH, Kim HS, Kim YW, Choi IJ, et al. (2003) Prediction of lymph nodes metastasis, by sentinel bode biopsy in gastric cancer. Surg Oncol 29(10): 895-999.

84. Martin SK, Murray FB (1998) Gastric Carcinoma. Ann Surg Oncol 57(7): 650-656

85. Nieweg OE, Tanis PJ, Kroon BB (2001) The definition of a Sentinel node. Ann Surg Oncol 8(6): 538-41.

86. HM Sue-Ling, D Johnston, IG Martin, MF Dixon, MR J Lansdown, et al (1993) Gastric cancer: a curable disease in Britain. Br 7 307(6904): 591-596.

87. Bilchik A, Guiliano A, Essmer R (1998) Universal application of intraoperative lymphatic. Cancer. Ann 4: 351-358.

88. Tsionlias G, Wood TF, Morton DL (2000) Lymphatic Mapping and Focused Analysis of Sentinel Lymph Nodes Upstage Gastrointestinal Neoplasms. Arch Surg 135(8): 926-932.

89. Kitagawa Y, Fuzuh, Mukai M (2000) The role of sentinel lymph node in gastrointestinal cancer. Surg Clin North Ann 80(6): 1799-1809.

90. Smith DD, Schwarz RR, Schwarz RE (2005) Impact of total lymph node count on staging and survival after gastrectomy for gastric cancer: data from a large US. Population Database. Clin Oncol 23(28): 7114-7124.

91. Brennan MF (2005) Current status of surgery for gastric cancer: a review. Gastric Cancer 8(2): 64-70.

92. Baxter NN, Tuttletin (2005) Inadeqvacy of lymphnode staging in gastric cancer patients: a population -based study. Ann Surg Oncol 12(12): 981-987

93. Coburn NG, Lourenco LG, Rossi SE, Gunraj N, Mahar AL, et al. (2010) Management of gastric cancer in Ontorio. Surg Oncol 102(1): 54-63. 


\section{Cancer Therapy \& Oncology International Journal}

94. Schascht U, Junemann A, Becker HJ, Huth F, Moschinski D, et al. (1974) Un metodo per vizualizzazione dei limfonadi gastrici mediante introduzione endoscopica di Lipiodal ultrafluido. Min Med 65: 4922 4925 .

95. Shen JY, Kim S, Cheong JH, Kim YI, Hyung WJ, et al. (2007) The impact of total retrieved lymph nodes on staging and survival of patients with pT3 gastric cancer. Cancer 110(4): 745-751.
96. Meyer H (2005) The influence of case local and the extent of resection on the quality of treatment outcome in gastric cancer. Eur Surg Oncol 31(6): 595-604

97. Brennan MF (2005) Current status of surgery for gastric cancer: a review. Gastric cancer 8(2): 64-70.
This work is licensed under Creative

Commons Attribution 4.0 License

DOI: 10.19080/CTOIJ.2019.13.555869
Your next submission with Juniper Publishers will reach you the below assets

- Quality Editorial service

- Swift Peer Review

- Reprints availability

- E-prints Service

- Manuscript Podcast for convenient understanding

- Global attainment for your research

- Manuscript accessibility in different formats

( Pdf, E-pub, Full Text, Audio)

- Unceasing customer service

Track the below URL for one-step submission https://juniperpublishers.com/online-submission.php 